\title{
Desenvolvimento das reações álcali-agregado em matriz de cimento Portland com sílica ativa e agregado reativo
}

\author{
R. Lima ${ }^{1 *}$, M. Valenga ${ }^{1}$, E. Pereira ${ }^{1,2}$, E. Pereira ${ }^{1,2}$. \\ *Autor de Contato: rubia_plc_10@hotmail.com \\ ${ }^{1}$ Departamento de Engenharia Civil, Universidade Estadual de Ponta Grossa, Ponta Grossa, Brasil \\ ${ }^{2}$ Programa de Pós-Graduação em Engenharia e Ciência de Materiais, Universidade Estadual de Ponta Grossa, Ponta \\ Grossa, Brasil.
}

\begin{abstract}
RESUMO
O presente trabalho tem como objetivo avaliar a influência do uso de sílica ativa no desenvolvimento das reações álcali-agregado em matriz de cimento Portland, acompanhando a evolução das reações em matriz cimentícia sob perspectiva de propriedades mecânicas como permeabilidade e resistência à compressão, sendo analisada a capacidade de mitigação da reação. Assim, variou-se de $0 \%$ a $15 \%$ o teor de substituição de sílica ativa em relação ao aglomerante. Foram realizados os ensaios acelerados paras as barras de argamassa, absorção por imersão, resistência à compressão e de microscopia eletrônica de varredura (MEV). As substituições de sílica ativa, em porcentagens acima de $10 \%$, mostraram-se eficientes para mitigar a reação, porém as propriedades mecânicas, para uma mesma relação água/cimento, tendem a serem afetadas.
\end{abstract}

Palavras chave: Durabilidade; Reação álcali-agregado; Sílica ativa.

\begin{abstract}
The follow study aims to evaluate the influence of silica fume on the development of alkaliaggregate reactions in Portland cement matrix, following the evolution of reactions in cementitious matrix from the perspective of mechanical properties such as permeability and compressive strength, being analyzed the reaction and mitigation capacity. Thus, the content of substitution of silica fume was varied from $0 \%$ to $15 \%$ in relation to the binder. Accelerated tests were carried out for mortar bars, immersion absorption, resistance to compression and scanning electron microscopy (SEM). The substitutions of silica fume are efficient to mitigate the reaction, in percentages above $10 \%$, however the mechanical properties, for the same water / cement ratio, tend to be affected.
\end{abstract}

Keywords: Durability; Alkali-aggregate reaction; Activated silica.

\section{RESUMEN}

El presente trabajo tiene como objetivo evaluar la influencia del uso de humo de sílice en el desarrollo de reacciones álcali-agregado en la matriz de cemento Portland, siguiendo la evolución 
de las reacciones en la matriz cementosa desde la perspectiva de propiedades mecánicas como la permeabilidad y la resistencia a la compresión, siendo analizado la capacidad de mitigación de la reacción. Así, el contenido de sustitución del humo de sílice varió de $0 \%$ a $15 \%$ en relación al aglutinante. Se realizaron pruebas aceleradas para barras de mortero, absorción por inmersión, resistencia a la compresión y pruebas de microscopía electrónica de barrido (SEM). Las sustituciones de humo de sílice son eficientes para mitigar la reacción, en porcentajes superiores al 10\%, sin embargo las propiedades mecánicas, para la misma relación agua / cemento, tienden a verse afectadas.

Palabras Clave: Durabilidad; Reacción álcali-agregado; Sílice activa.

\section{INTRODUÇÃO}

O concreto é um material utilizado em escala mundial, estando presente nas mais diversas formas e tipos de construção. Apesar de ser um material resistente e com grande capacidade estrutural, o concreto está sujeito a alterações ao longo do tempo, que dependem de seus materiais constituintes e da agressividade ambiental do meio ao qual está inserido. Dessa forma, através da interação da estrutura de concreto com o meio, podem ocorrer manifestações deletérias, que colocam em risco a durabilidade da estrutura, e, consequentemente, a sua vida útil (Tiecher, 2006). Segundo Neville (2016), a perda da durabilidade do concreto se manifesta pela sua deterioração, que pode ocorrer tanto de fatores externos quanto internos, sendo essas reações de origem física ou química.

A reação álcali-agregado (RAA) apresenta-se como um mecanismo de degradação do concreto, sendo um processo químico que envolve íons alcalinos ( $\mathrm{Na}$ e $\mathrm{K}$ ), provenientes principalmente da hidratação do cimento, íons hidroxilas $\left(\mathrm{OH}^{-}\right)$e os constituintes mineralógicos dos agregados (Vadulga, 2002). Como resultado desta reação é formado um gel viscoso e higroscópico, que tende a atrair moléculas de água, capazes de expandir-se, gerando fissuras em seu entorno, podendo comprometer a microestrutura do concreto (Hasparyk, 2005). No entanto, para que ocorra essa reação deletéria, é necessário que ocorram três fatores simultaneamente, sendo eles, a presença de agregados reativos, umidade e concentração de álcalis acima do limite crítico (Olliver; Vichot, 2014). As manifestações mais comuns verificadas em estruturas de concreto afetadas pela RAA são fissurações do tipo mapa, exsudação do gel na superfície do concreto, bordas de reação ao redor dos agregados, preenchimento de poros com material esbranquiçado, microfissuração e descoloração do concreto (Poole, 1992; Furnas 1997; Hasparyk, 1999). Em casos avançados da reação, o concreto tende a perder a resistência mecânica (Metha; Monteiro, 2008).

Para evitar a ocorrência da reação álcali-agregado, uma opção seria utilizar agregados que são comprovadamente não reativos, porém, isso nem sempre é possível e viável economicamente. Mantendo-se o agregado reativo, deve-se utilizar cimentos que possuam baixo teor de álcalis, assim como as adições pozolânicas, tais como a sílica ativa, metacaulim, cinza volante ou pozolanas naturais (Hasparyk, 2005). Segundo Dal Molin (2005) as adições minerais produzem um efeito químico na microestrutura do concreto, sendo este associado à capacidade de reação com o hidróxido de cálcio $\left(\mathrm{Ca}(\mathrm{OH})_{2}\right)$, formado durante a hidratação do cimento Portland, para formar silicato de cálcio hidratado $(\mathrm{C}-\mathrm{S}-\mathrm{H})$ adicional, responsável pela resistência das pastas de cimento hidratadas. Essas adições são eficientes em inibir as reações expansivas resultantes da combinação dos álcalis do cimento com os agregados potencialmente reativos. Isso se deve a três fatores, sendo eles, redução da permeabilidade do concreto; ocorrência da redução total de álcalis do aglomerante ao se substituir parte do cimento; consumo de parte dos álcalis pela reação pozolânica, ao invés da reação com os agregados reativos.

A incorporação de adições minerais à composição do cimento propicia vantagens econômicas e ambientais, além de interferir na microestrutura da matriz hidratada, incrementando, na maioria das vezes, a durabilidade da obra com esse material ligante (Hoppe Filho et al., 2013).Entretanto, 
é necessário que investigações sejam realizadas a fim de conhecer a eficiência de cada material e para determinar a ação ótima com o agregado reativo, caso contrário, ao invés de estar reduzindo as expansões, um efeito inverso poderá ocorrer (Silva, 2007).

Entre os materiais pozolânicos usados para adição, apresenta-se a sílica ativa. A sílica ativa é oriunda do processo de produção das indústrias de ferrosilício e silício-metálico. Devido à sua extrema finura e silício amorfo, a sílica ativa é um material muito reativo. A adição da sílica ativa influencia a espessura da zona de transição nas argamassas e o grau de orientação dos cristais de $\mathrm{CH}$ nela. Assim, a espessura da zona de transição (ZT) comparada à argamassa contendo apenas cimento Portland comum diminui. Portanto, as propriedades mecânicas e a durabilidade são aprimoradas devido melhora da resistência interfacial. $\mathrm{O}$ mecanismo não está apenas conectado à formação química de C-S-H na interface dos agregados e pasta, mas também a modificação da microestrutura, porosidade e espessura da zona de transição (Khan; Siddique, 2011).

Diante da relevância do estudo da reação álcali-agregado e as incertezas presentes em relação a este assunto, torna-se importante a realização de pesquisas para a mitigação da reação. No presente trabalho, foi avaliada a influência do uso da sílica ativa no desenvolvimento da RAA, sendo feita a substituição de cimento Portland por sílica ativa em diferentes teores com o objetivo de acompanhar a evolução das reações em matriz cimentícia sob a perspectiva de propriedades mecânicas como permeabilidade e resistência à compressão, sendo analisada a capacidade de mitigação da reação álcali-agregado.

\section{PROCEDIMENTO EXPERIMENTAL}

Foi realizado o ensaio acelerado das barras de argamassa conforme a norma americana ASTM C 1260/07, que visa analisar a reatividade álcali-agregado, no traço constante de 1:2,25:0,47. A quantidade de cimento para o ensaio foi de $440 \mathrm{~g}$ e $990 \mathrm{~g}$ de agregado para um relação a/c=0,47. O agregado utilizado foi obtido por britagem de rocha granítica sã, sendo que este mostrou-se reativo aos álcalis em pesquisa anterior realizada pelo grupo de pesquisa em materiais de construção da Universidade Estadual de Ponta Grossa. O cimento utilizado foi CP II F - 32. As condições de mistura da argamassa foram procedidas de acordo com a NBR 7215 (ABNT, 1996). Dessa forma, a adição de sílica ativa foi utilizada como substituição parcial da massa de cimento Portland nas porcentagens de $0 \%$ (referência), 5\%,10\% e 15\% com três barras por porcentagem, totalizando doze barras. Com a moldagem das barras, foi realizado o monitoramento das expansões lineares das amostras imersas em solução de hidróxido de sódio $(\mathrm{NaOH})$, na concentração de $40 \mathrm{~g}$ para cada litro de água $(1 \mathrm{~mol})$, mantida a uma temperatura controlada em $80 \pm 2{ }^{\circ} \mathrm{C}$. Foram feitas medidas de expansão semanalmente, sendo que na Figura 1 apresentam-se as barras no momento em que estas foram desmoldadas.

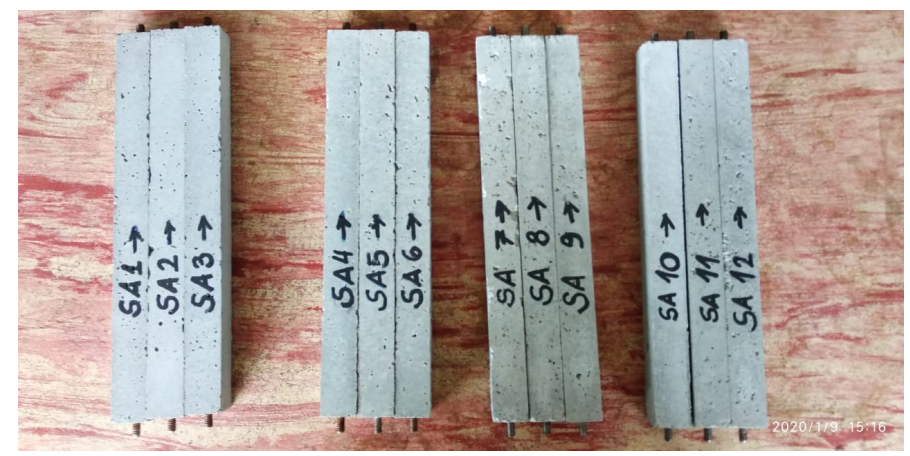

Figura 1 - Barras de argamassa estudadas

Para análise das resistências mecânicas e absorções por imersão formam moldados corpos de prova de argamassa de 5,0 de diâmetro por 10,0 cm de altura, atendendo as recomendações da NBR 7215 
(ABNT, 1996), com o mesmo traço estabelecido para o ensaio acelerado. Ainda realizou-se o ensaio do índice de consistência da argamassa, na mesa de abatimento, conforme a NBR 13276 (ABNT, 2016), para análise das suas propriedades no estado fresco. Já o ensaio de absorção por imersão foi realizado de acordo com a NBR 9778 (ABNT, 1987), para análise das propriedades de absorção.

Foram moldados 48 corpos de prova de argamassa, sendo doze corpos de prova para cada porcentagem de substituição, para porcentagens de $0 \% .5 \%, 10 \%$ e $15 \%$. Os corpos de prova moldados, foram submetidos nas mesmas condições de cura acelerada em hidróxido de sódio. Estes corpos de prova foram utilizados para a execução dos ensaios de absorção e de resistência à compressão aos 28 dias e aos 60 dias. Depois de realizados esses ensaios, foram feitas amostras a partir dos corpos de prova para ensaios de microscopia eletrônica de varredura, no qual foram verificadas as alterações microestruturais ocorridas nas argamassas pelo uso da adição.

\section{RESULTADOS}

Os resultados obtidos no ensaio do índice de consistência da argamassa no estado fresco estão apresentados na Figura 2. Pode-se observar que quanto maior a porcentagem de substituição de sílica ativa, menor é a consistência da argamassa, sendo que a adição de sílica ativa ocasionou uma redução na trabalhabilidade da argamassa. Isto ocorre principalmente pela finura da adição mineral, a qual tem a capacidade de maior retenção de líquidos devido a sua grande área superficial da soma de suas partículas.

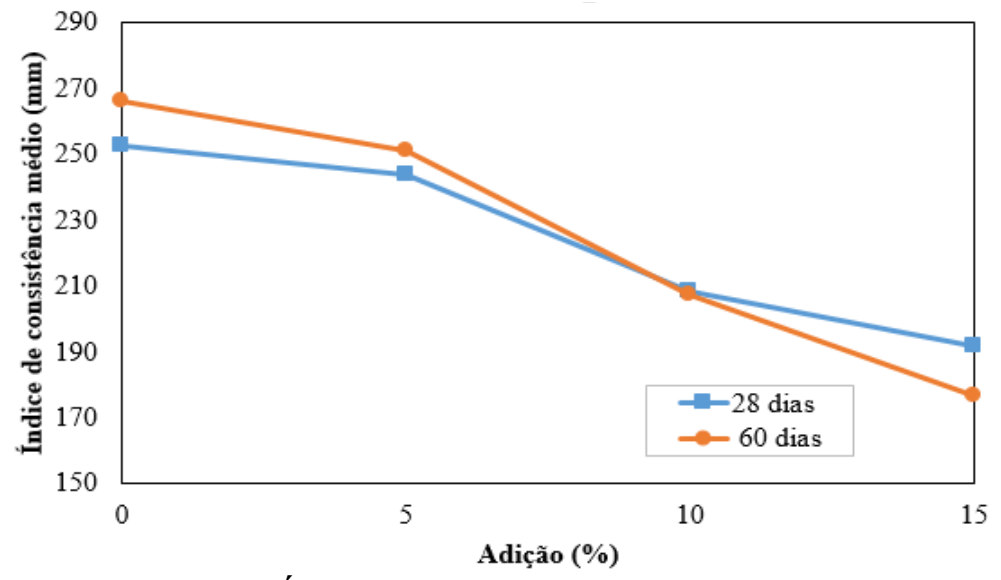

Figura 2 - Índice de consistência aos 28 e 60 dias

Optou-se neste estudo em não utilizar aditivo para correção do índice de consistência, visando o estudo da interação da sílica ativa nas demais propriedades no estado endurecido das argamassas assim como na microestrutura destas. As consistências praticadas neste trabalho foram suficientes para que as moldagens fossem adequadas, não interferindo negativamente neste processo.

Segundo a ASTM C - 1260, 2007, para o método acelerado das barras de argamassa, em um período de 16 dias, se a expansão for superior ou igual a $0,2 \%$ o agregado é considerado como deletério, se estiver entre $0,2 \%$ e $0,1 \%$ é considerado como potencialmente deletério e se for inferior a $0,1 \%$ é considerado como inócuo.

A Figura 3 apresenta as variações dimensionais das barras de argamassa após o ensaio acelerado. As barras com 5\% de substituição de sílica ativa demonstram que a adição não apresentou capacidade de mitigar a reatividade do agregado, o qual se torna potencialmente deletério aos 10 dias e passa a ser deletério aos 20 dias. Já as substituições de sílica ativa de $10 \%$ e de 15\% mostraram-se eficientes para mitigar a reação, reduzindo o seu coeficiente de expansão aos limites recomendados aos 16 dias. 


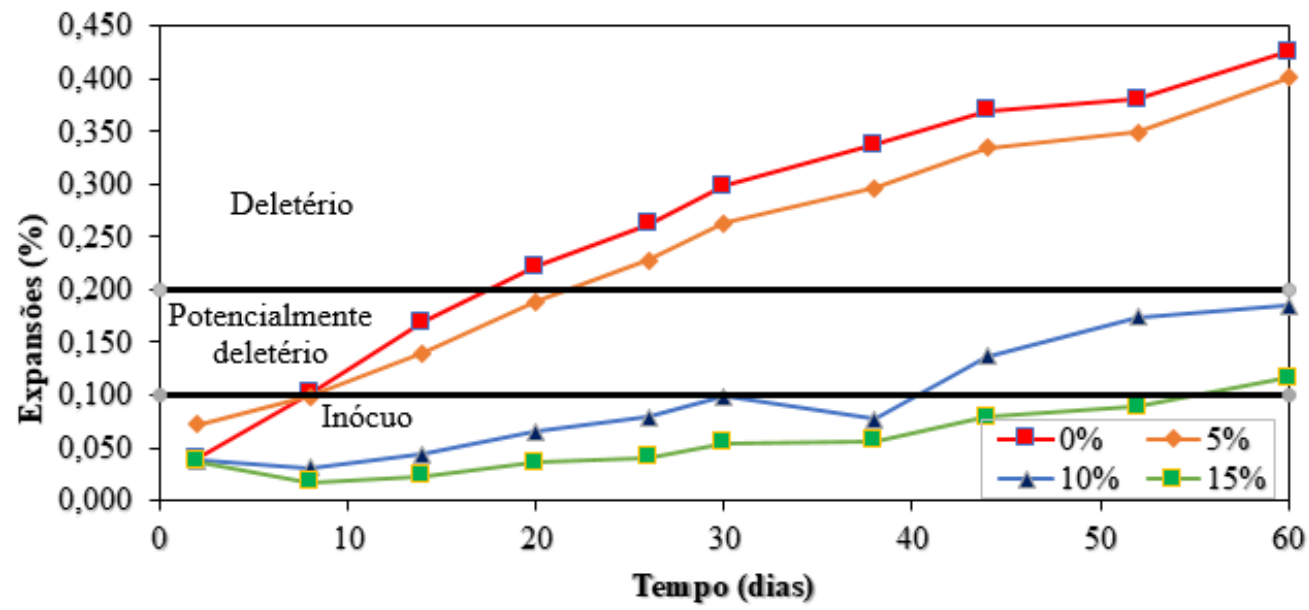

Figura 3 - Expansão (\%) x Tempo (dias)

Baptista et al., (2013) observaram comportamento similar em seu estudo, sendo que foram utilizadas adições de $5 \%, 15 \%$ e $25 \%$ em relação a massa de cimento, corroborando com os dados encontrados neste trabalho. Munhoz (2007) apresentou em seu trabalho que a partir de 10\% de adições de sílica ativa já são suficientes para que as expansões causadas pela RAA sejam reduzidas para menos de 0,10\% aos 14 dias segundo a ASTM C 1567.

Observa-se, pela Figura 4, que as resistências à compressão aos 28 dias são maiores nas proporções de substituição de cimento por sílica ativa de $0 \%$ e de $5 \%$, diminuindo nas substituições de $10 \%$ e de $15 \%$. Aos 60 dias o mesmo comportamento é observado, mas já a partir da substituição de $5 \%$ são observadas quedas acentuadas na resistência mecânica. Este comportamento pode ser explicado pelo fato de as reações pozolânicas ainda não terem ocorrido completamente, assim como pela insuficiência destas em aumentar a resistência a ponto de se equiparar com o cimento Portland.

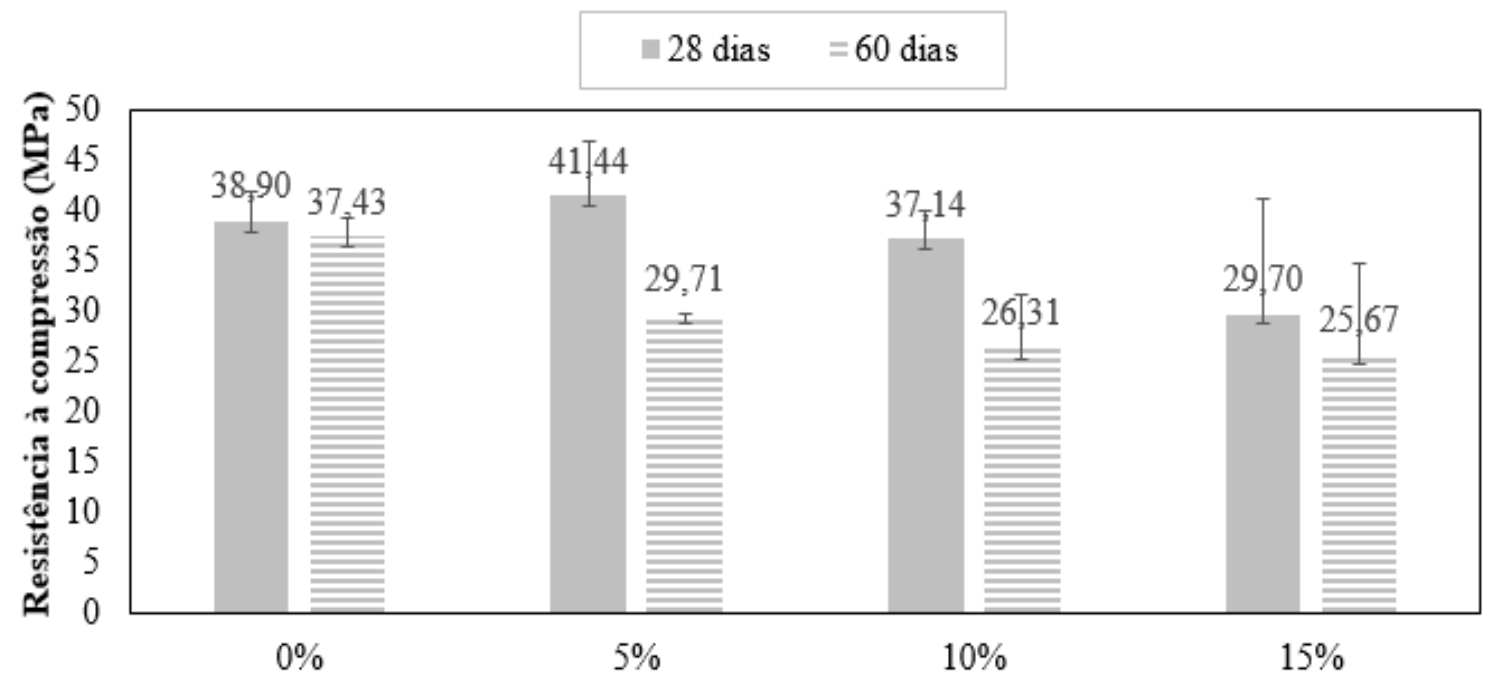

Figura 4 - Resistência à compressão aos 28 e 60 dias.

Outra explicação para este comportamento de redução das resistências mecânicas é que os produtos formados pela RAA podem tamponar os poros e aumentar a resistência em estágios iniciais, como aos 28 dias de cura, onde tal caraterística auxiliaria nas maiores resistência nos traços com maior ocorrência de RAA. Com a intensificação da RAA, a tendência é a formação de tensões internas devido a formação de produtos expansíveis e higroscópicos na fase dos agregados, ocasionando assim a perda de resistência pela ocorrência de fissurações (Pereira, 2018). 
As maiores resistências aos 28 dias em relação aos 60 dias, de forma geral, demonstram a intensificação da RAA mesmo com altos teores de substituição de cimento por sílica ativa. A literatura apresenta ainda que a RAA tem a tendência de apresentar dormência inicial das reações, sendo que posteriormente as reações formam poros pela dissolução de fases reativas do agregado assim como pela geração de fissuras devido à expansão dos produtos gerados, sendo ainda demonstrada a ocorrência da colmatação de poros pela diminuição da absorção e porosidade. Garcia-Diaz et al., (2006), observaram comportamento similar em seus estudos, onde a dormência inicial das reações é seguida pela colmatação de poros e alteração das características dos materiais.

Pereira (2018), identificou mesmo comportamento em seu estudo, sendo que em idades iniciais as resistências mecânicas tendem a aumentar com os efeitos da RAA, apresentando posteriores quedas devido a sua intensificação.

Para o ensaio de absorção por imersão nos corpos de prova, tanto aos 28 dias quantos aos 60 dias, observou-se uma estagnação das variações dessa propriedade em relação aos traços estudados, visto que não foram apresentadas grandes variações nos resultados obtidos, variando entre 9,5\% aos 28 dias e 8,5\% aos 60 dias. Isto pode estar relacionado com as adições ativas que contribuem para o refinamento do tamanho dos poros na estrutura de pastas hidratadas, mas tendem a aumentar a porosidade total. Por outro lado, o produto da RAA gerado no ensaio acelerado, pelo processo da formação de géis expansíveis e, pela colmatação dos poros, contribui para a redução da porosidade total da argamassa. Os resultados de absorção estão apresentados na Figura 5.

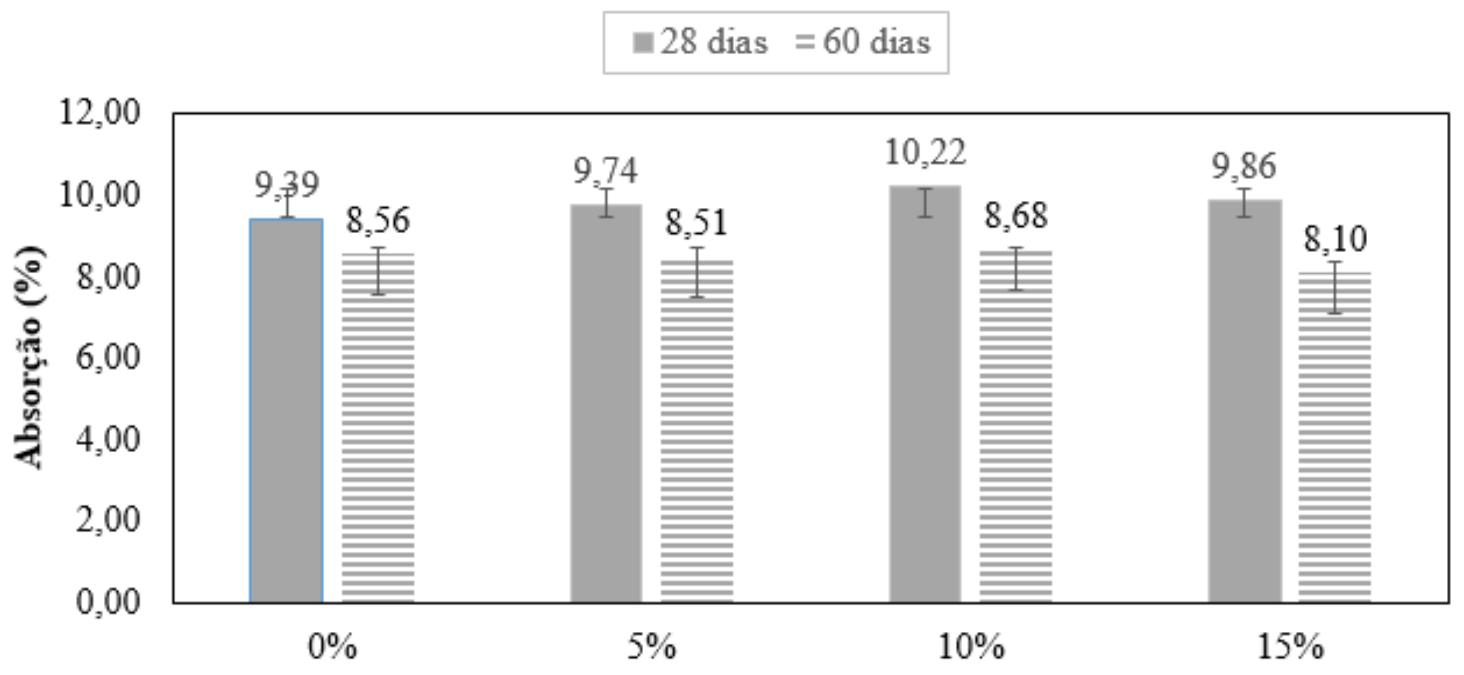

Figura 5 - Teores de absorção por imersão aos 28 e 60 dias

A Figura 6 apresenta as microscopias das amostras sem adição de sílica ativa, sendo a Figura 6(a) demonstrando a característica de reatividade dos agregados, devido, principalmente, ao ângulo de extinção ondulante (AEO), onde os cristais sofrem deformações e falta de arranjo de grande alcance, favorecendo a dissolução pelos álcalis. A Figura 6(b) apresenta os produtos da RAA, sendo este um gel expansivo, o qual aparece em grande quantidade devido à alta reatividade do agregado. 

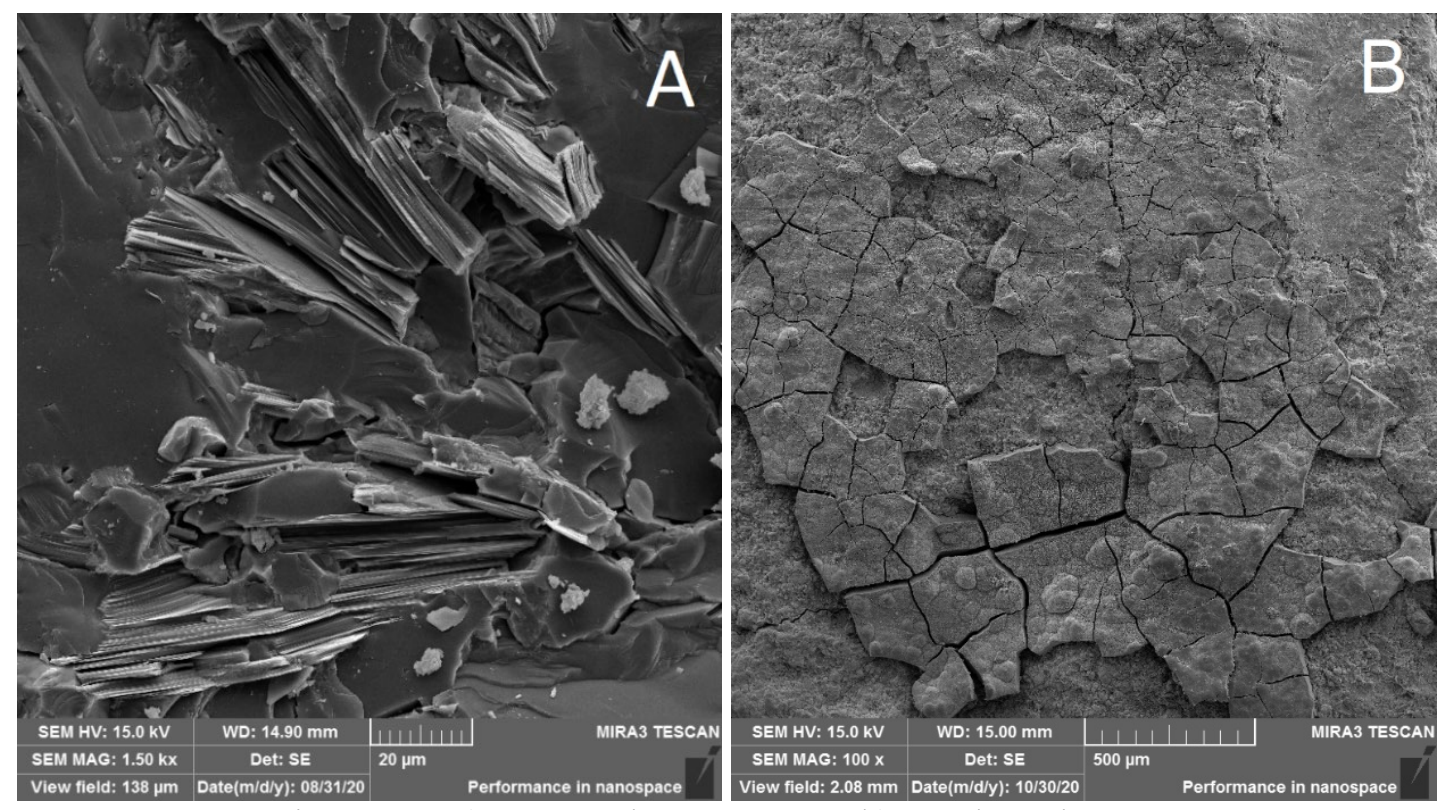

Figura 6 - a) Agregado com AEO; b) Produto da RAA

A Figura 7 apresenta a análise de EDS do gel formado nas argamassas sem a adição de sílica ativa. É importante destacar que a tabela dos elementos químicos é semi-qualitativa, não podendo ser utilizada para afirmar com precisão as porcentagens dos compostos na amostra e um cálculo estequiométrico exato. Identifica-se por meio do EDS, a presença de majoritária de oxigênio, sódio, sílica e cálcio, elementos característicos dos géis de RAA. O cálcio geralmente substitui os íons sódio ou potássio, tornando o gel denso e menos solúvel, conforme pode ser observado na microscopia (Hasparyk, 2005).

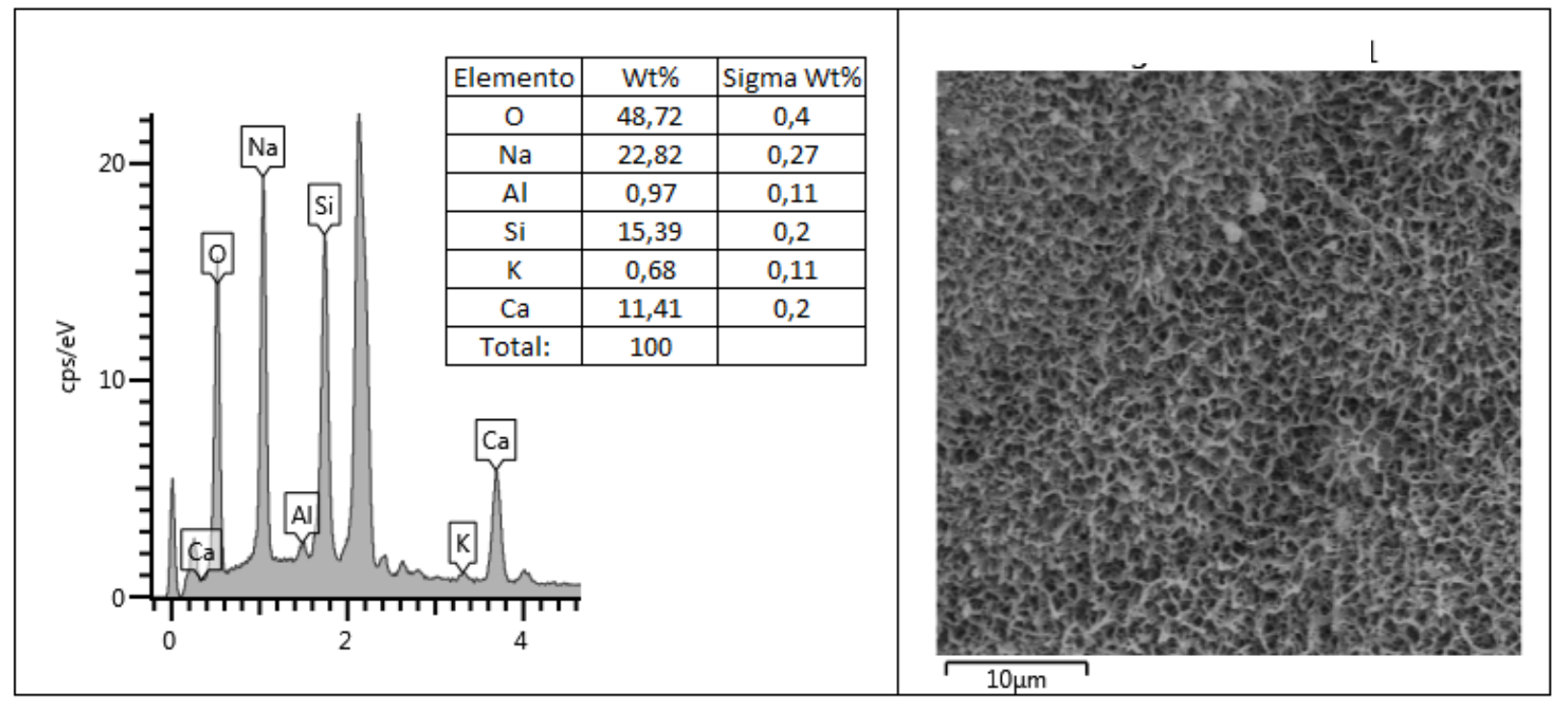

Figura 7 - Análise de EDS do gel formado nas argamassas com $0 \%$ de adição de sílica ativa

Nas amostras com 5\% de substituição de sílica ativa (Figura 8 (a)), foi possível observar que, mesmo em pequena quantidade, a substituição de cimento por sílica ativa promoveu a formação de uma camada particulada mais densa sobre os produtos da RAA, demonstrando que a sílica tem capacidade de densificar os géis formados, diminuindo assim os efeitos da reação álcali-agregado. Destaca-se que, mesmo observando alterações na morfologia dos produtos formados nas microscopias, nos ensaios de variação dimensional das barras de argamassa os resultados 
demonstraram que tal porcentagem de substituição não foi suficiente para reduzir as expansões a limites aceitáveis perante as normativas. A Figura 8 (b) apresenta uma imagem mais detalhada do gel formado na parede de um dos poros da argamassa, sendo possível identificar a formação de cristais aciculares neste material.
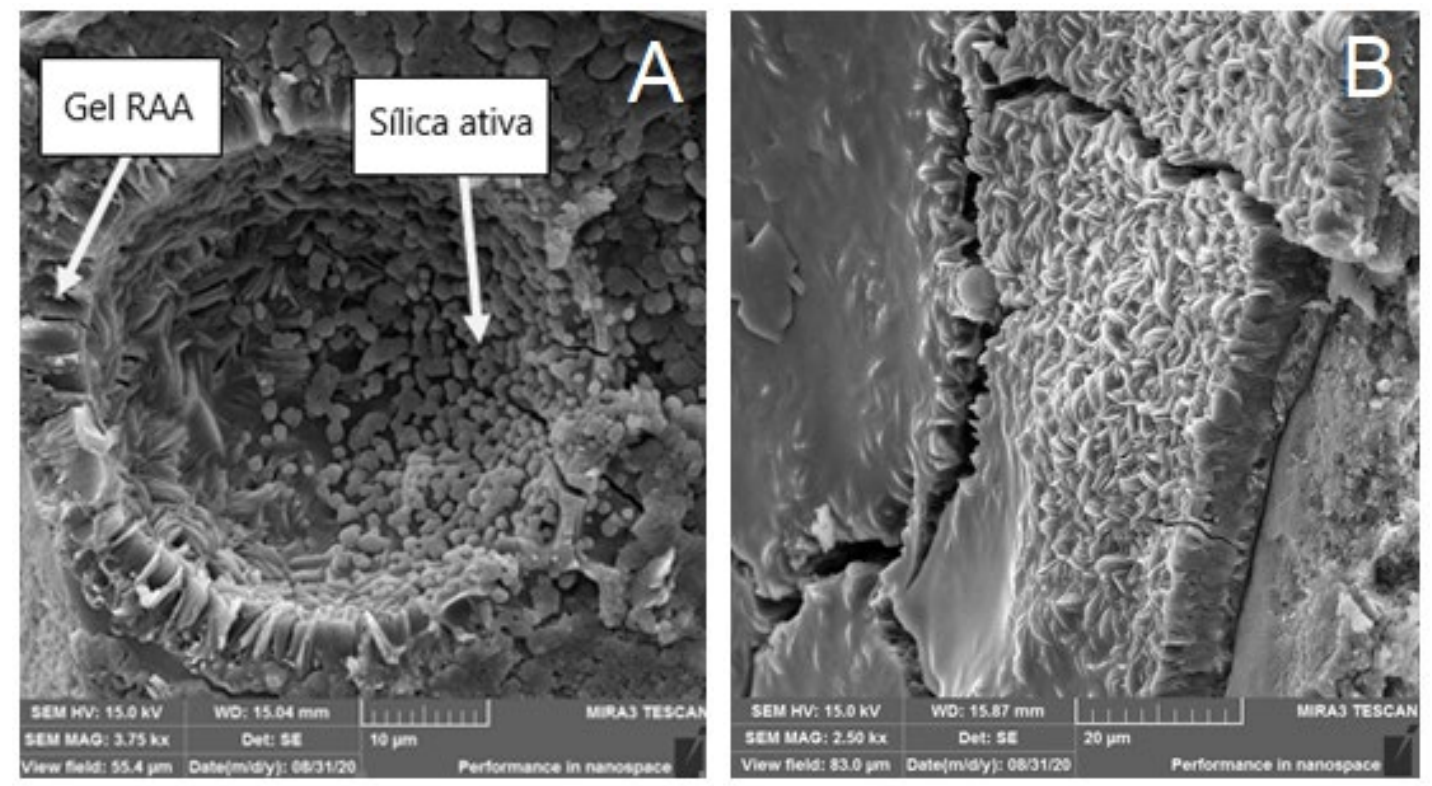

Figura 8 - a) Poro de argamassa com 5\% de substituição de sílica ativa; b) Presença de gel com cristalizações na parede dos poros

A Figura 9 apresenta a análise de EDS dos produtos formados nos poros das argamassas com 5\% de substituição de sílica ativa, sendo possível observar predominantemente álcalis como sódio e cálcio assim como silício. Tais produtos são típicos da ocorrência da RAA, corroborando o que foi observado nos ensaios de variações dimensionais das barras de argamassa. Destaca-se que este gel foi encontrado massivamente dentro de poros e vazios na matriz cimentícia.

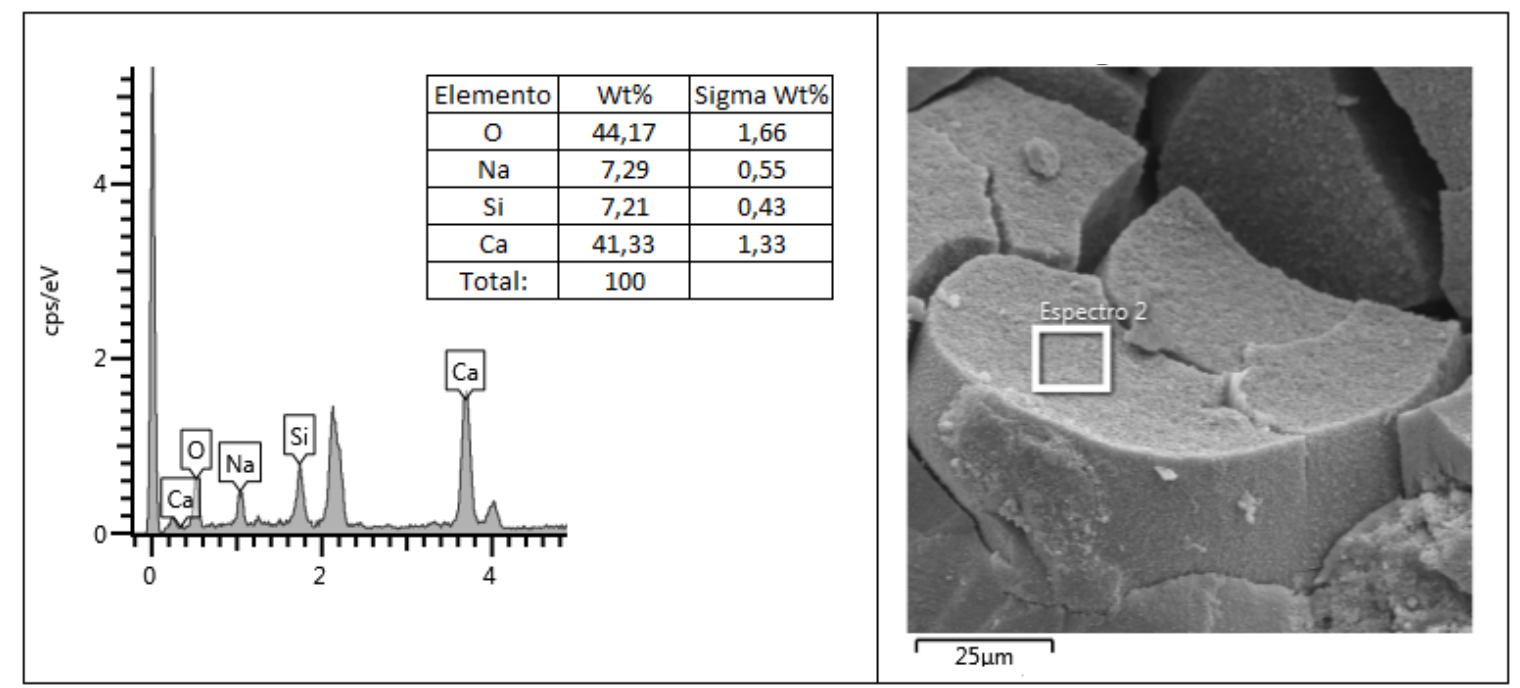

Figura 9 - Análise de EDS do gel formado nas argamassas com 5\% de adição de sílica ativa

Nas amostras de 10\% de sílica ativa foi possível observar um aumento considerável de cristais de silicato de cálcio nas microscopias e por EDS, sendo que isto demostra que as reações pozolânicas estão ocorrendo na matriz cimentícia, podendo-se observar este efeito nas expansões das barras de 
argamassa, pois nesta porcentagem de substituição a adição é eficiente para mitigar a reação deletéria. Na Figura 10(a) identifica-se os cristais característicos dos silicatos de cálcio na matriz da argamassa, sendo que na Figura 10(b) é possível observar estes cristais em uma maior magnificação, sendo que estes se encontram aderidos na parede dos poros, diminuindo a incidência de gel reativo e por consequência as expansões como observado nos ensaios acelerados.
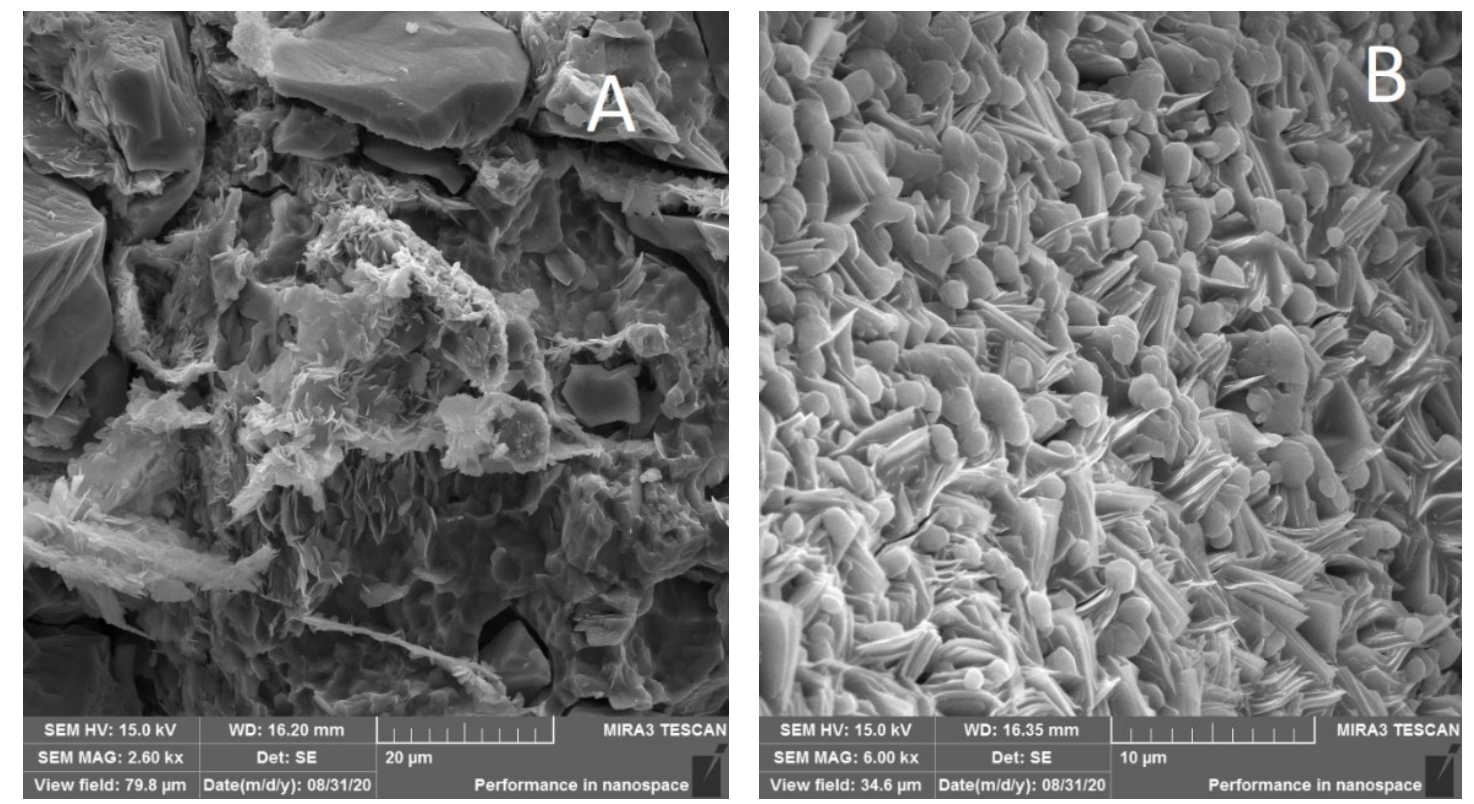

Figura 10 - a) Estruturas formadas no agregado reativo; b) Estruturas formadas nos poros de argamassa.

Na Figura 11, apresenta-se a análise EDS dos produtos formados na parede dos poros da argamassa com 10\% de substituição de cimento. Tal análise demonstra que o material é rico em silício e cálcio, comprovando as afirmações anteriores de que silicatos de cálcio hidratados foram formados divido aos efeitos pozolânicos da sílica ativa. Tais comportamentos eram esperados segundo a bibliografia, mas objetivava-se a identificação e caracterização destes materiais na microestrutura das argamassas.

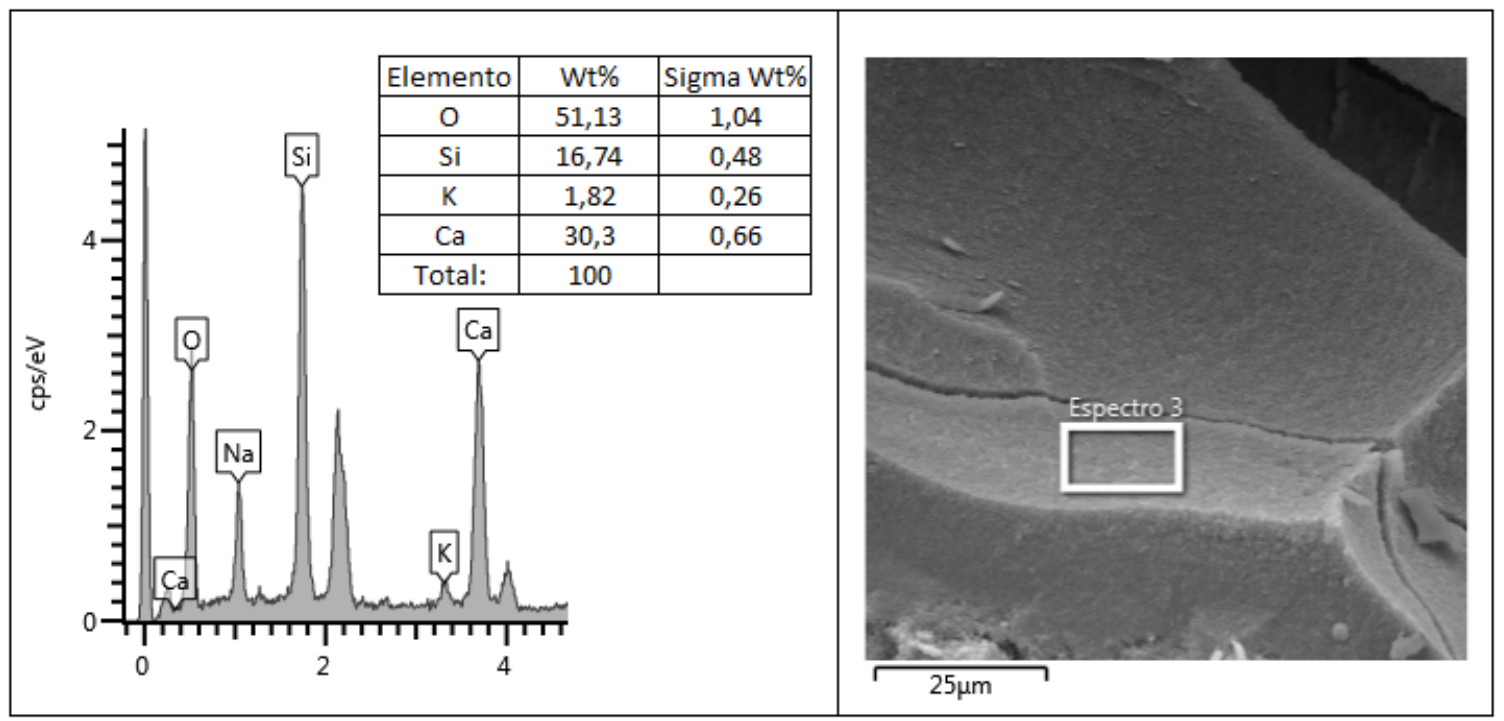

Figura 11 - Análise de EDS do gel formado nas argamassas com 10\% de adição de sílica ativa 
Nas amostras com 15\% de substituição foram identificadas a formação de estruturas de silicato de cálcio tanto nos agregados reativos quanto nos poros das argamassas. Nas Figuras 12(a) e 12(b) pode-se identificar a grande formação destes cristais, e a sua densificação frente aos géis álcaliagregados. Estas formações tiveram a capacidade de reduzir consideravelmente as expansões que puderam ser observadas no ensaio acelerado, demonstrando que a sílica ativa tem a capacidade de mitigar as ocorrências da RAA.
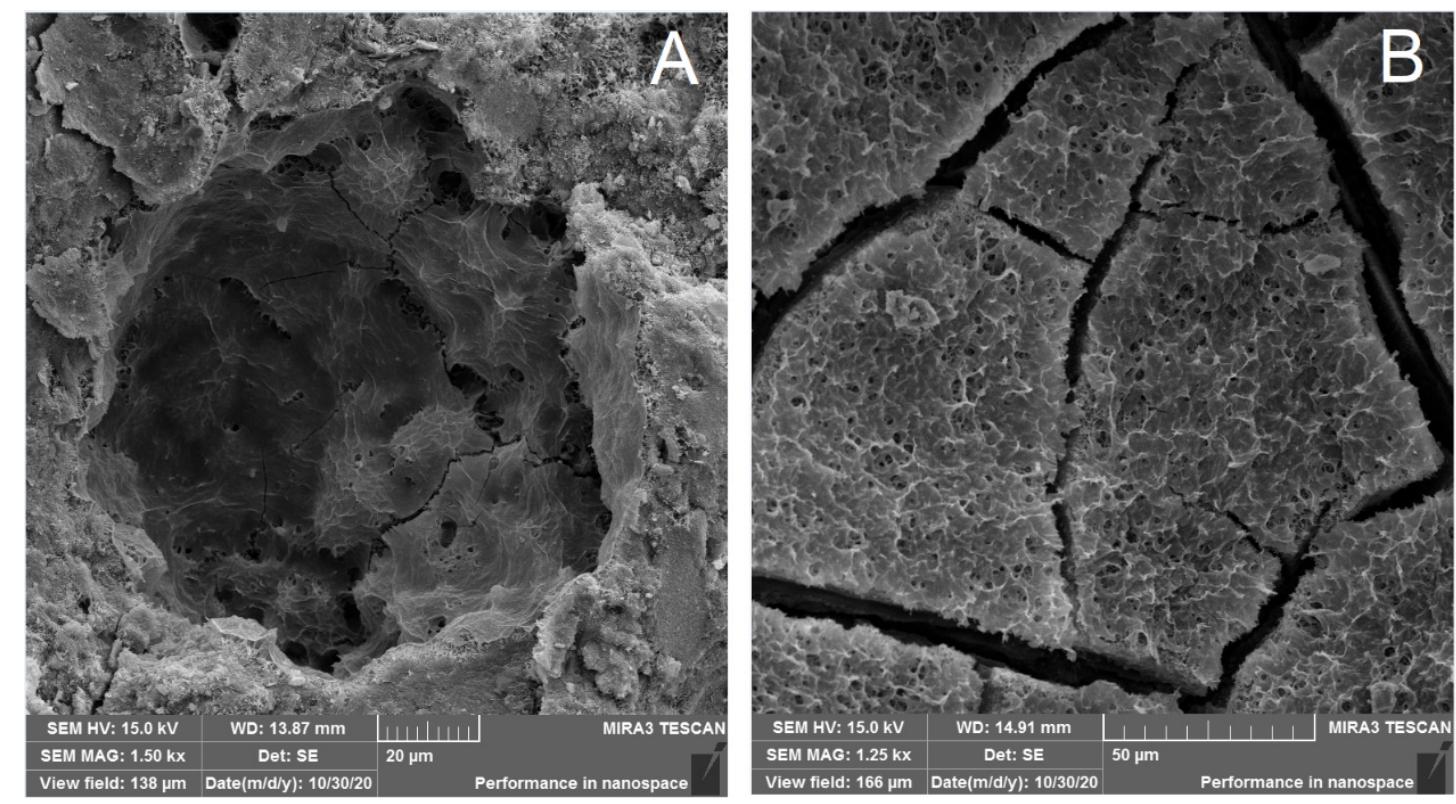

Figura 12 - a) Camada de silicato de cálcio na parede de poro; b) Detalhe dos produtos formados

Nas amostras com 15\% de substituição (Figura 13) observou-se ainda a formação de nucleações das partículas de sílica ativa, demonstrando a grande afinidade deste material em formar produtos densos e não reativos.

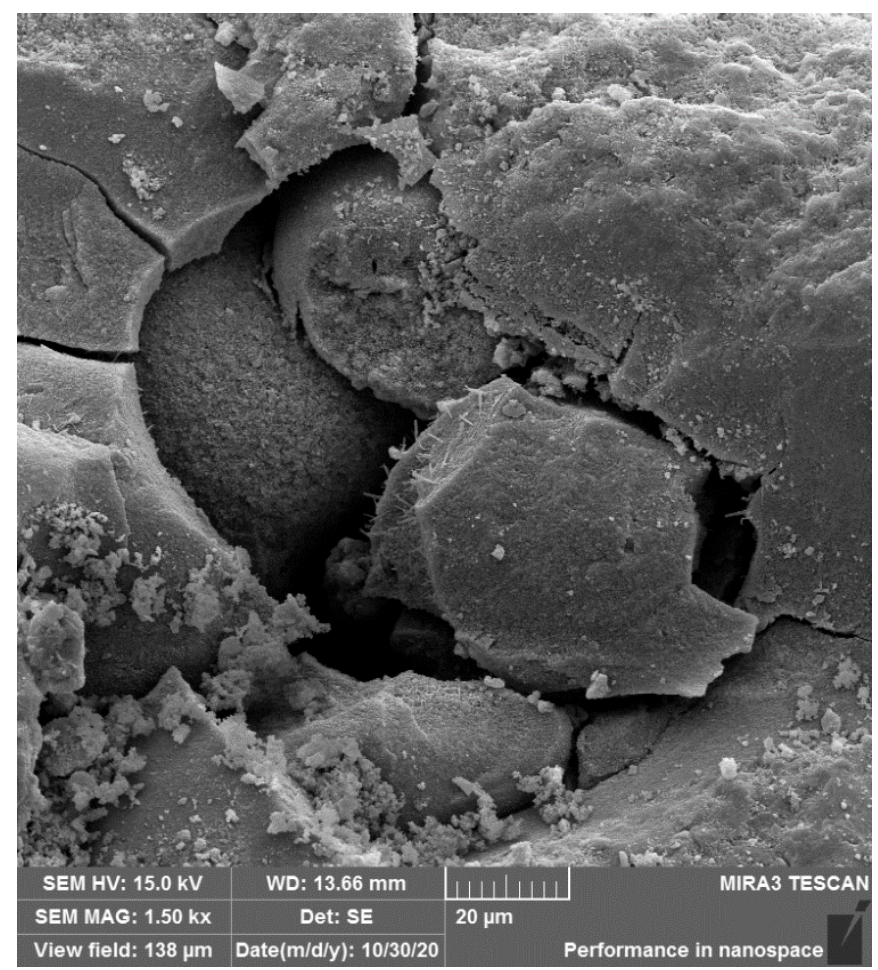

Figura 13 - Amostras com 15\% de substituição de sílica ativa. 
As figuras 14 (a) e 14 (b) demonstra os poros das argamassas sem adição de sílica ativa e com 15\% de substituição respectivamente.
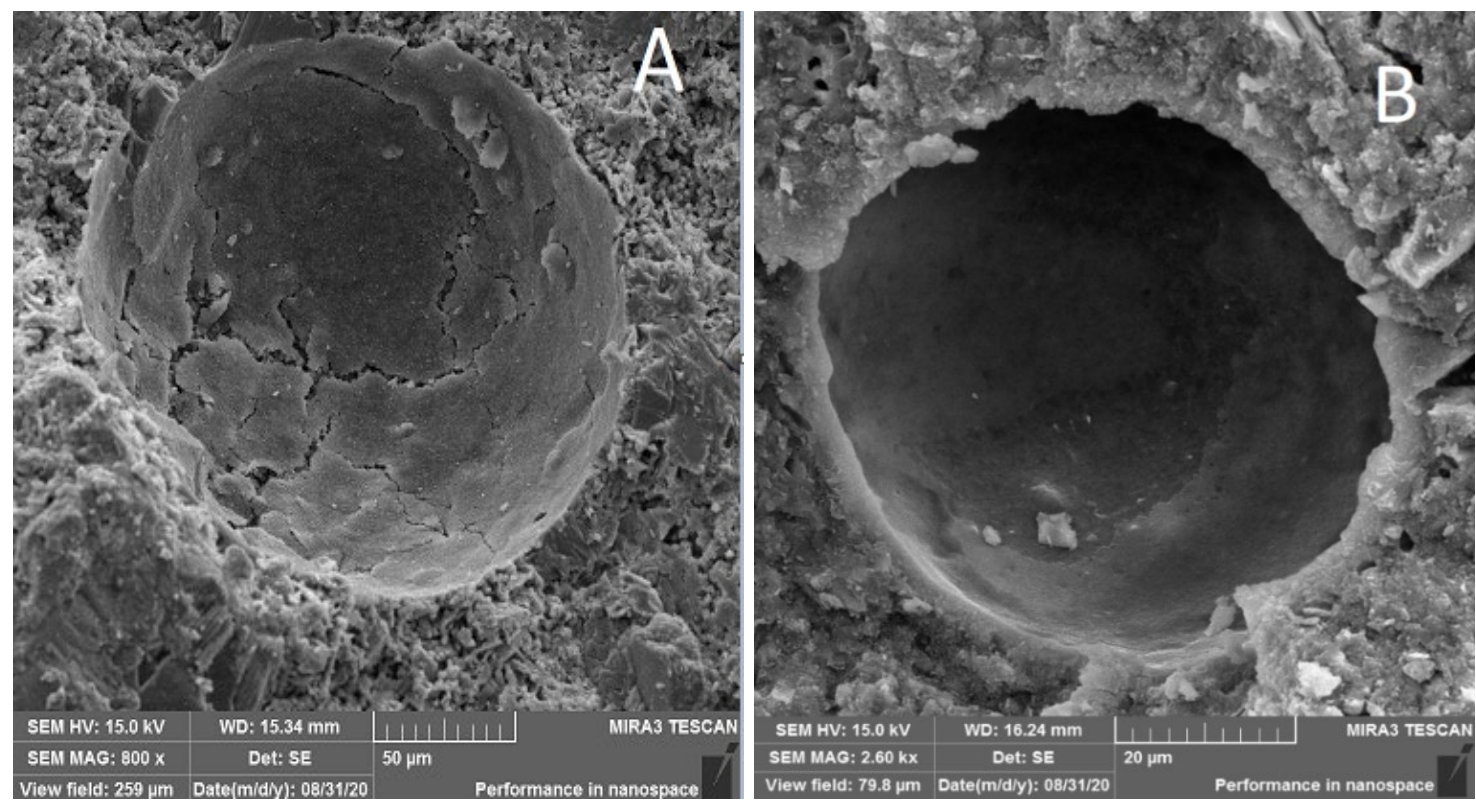

Figura 13 - a) Poro da argamassa sem sílica ativa; b) Poro da argamassa com $15 \%$ de sílica ativa

Fazendo-se uma comparação entre as argamassas sem adição de sílica ativa e com o maior percentual de $15 \%$, pode-se observar que ocorre a formação do gel característico da reação álcaliagregado nos poros da matriz cimentícia e fissurações formadas pela expansão do gel na argamassa sem sílica ativa. Com o aumento da substituição parcial de sílica ativa foi possível observar uma diminuição nos produtos formados pela RAA, bem como a presença de partículas e cristais de silicato de cálcio, o que pode indicar a mitigação dos efeitos deletérios da reação álcali-agregado.

\section{CONCLUSÃO}

A substituição parcial da sílica ativa em relação ao cimento apresentou potencial de mitigação da reação álcali-agregado, nas porcentagens entre $10 \%$ e $15 \%$ de substituição. Os resultados indicam que estes teores são capazes de reduzir o seu coeficiente de expansão aos limites recomendados aos 16 dias.

Quanto as propriedades no estado fresco, a adição de sílica ativa ocasionou uma redução na trabalhabilidade das argamassas, o que ocorre principalmente pela finura da adição. As maiores resistências mecânicas aos 28 e 60 dias ocorreram nas porcentagens com maior ocorrência de RAA, o que pode ter ocorrido pelo fato de as reações pozolânicas terem de forma conjunta com a RAA, tamponando os poros pelos produtos destas reações. Além disso, as maiores resistências ocorreram nos traços com maior quantidade de cimento Portland, demonstrando que as reações pozolânicas oriundas da sílica ativa não tem a capacidade de gerar resistências iguais às do cimento.

As variações de absorções não apresentaram um padrão, decorrente de que as adições ativas tendem a aumentar a porosidade total e os produtos da RAA contribuem para a redução da porosidade total da argamassa. Deve-se atentar ao fato de que quanto maior a porcentagem substituição, para uma mesma relação água cimento, as propriedades mecânicas das argamassas tendem a serem afetadas. Com o aumento da substituição parcial de sílica ativa, através dos ensaios de microscopia, foi possível observar uma diminuição nos produtos formados pela RAA e, também, a formação de partículas e cristais de silicato de cálcio, indicando a mitigação dos efeitos deletérios da reação álcali-agregado principalmente pela pozolanicidade da sílica ativa. 


\section{AGRADECIMENTOS}

A Universidade Estadual de Ponta Grossa pela concessão de Bolsa e pela infraestrutura de seus laboratórios, em especial ao Complexo Multiusuários C-LABMU. Ao CNPq pelo auxílio financeiro através da bolsa de estudos.

\section{REFERENCIAS}

ASMT International. (2007). ASTM C - 1260/07: Standard Test Method for Potential Alkali Reactivity of Aggregates (Mortar-Bar Method). Philadelphia, DOI: 10.1520 / C1260-07

Associação Brasileira De Normas Técnicas. (2008a). NBR 15577-1: agregados - reatividade álcali-agregado - parte 1: guia para avaliação da reatividade potencial e medidas preventivas para o uso de agregados em concreto. Rio de Janeiro.

Associação Brasileira de Normas Técnicas. (1996). NBR 7215: Cimento Portland - Determinação da resistência à compressão. Rio de Janeiro.

Associação Brasileira de Normas Técnicas. (2016). NBR 13276: Argamassa para assentamento e revestimento de paredes e tetos - Determinação do índice de consistência. Rio de Janeiro.

Associação Brasileira de Normas Técnicas. (2018). NBR 15577-5: Agregados - Reatividade álcaliagregado Parte 5: Determinação da mitigação da expansão em barras de argamassa pelo método acelerado. Rio de Janeiro.

BAPTISTA, Allan Silveira; HÖEHR, Guilherme Trindade; DAL MOLIN, Denise Carpena Coitinho. Avaliação da reação álcali-agregado da areia natural da região metropolitana de Porto Alegre, Brasil e do uso de sílica ativa. Porto Alegre: Universidade Federal do Rio Grande do Sul, 2013.

DAL MOLIN, D. C. C. (2005), “Adições minerais para concreto estrutural”. In: ISAIA, G. (Org). Concreto: ensino, pesquisa e realizações. São Paulo: IBRACON.

FURNAS, Equipe de Laboratório de Concreto; ANDRADE, W.P. (Ed). (1997), "Reatividade potencial álcali-agregado. In: Concretos massa estrutural, projetado e compactado com rolo: ensaios e propiedades". São Paulo.

GARCIA-DIAZ, E. et al. Mechanism of damage for the alkali-silica reaction. Cement and concrete research, v. 36, n. 2, p. 395-400, 2006.

PEREIRA, E. (2018), "Efeito da Reação Álcali-Agregado (RAA) Associada ao Ataque Interno por Sulfato (ISA) na Absorção e Porosidade de Compósito de Matriz Cimentícia”. Dissertação de Mestrado, Universidade Estadual de Ponta Grossa.

POOLE, A. B. (1992), “Introduction to alkali-aggregate reaction in concrete”. In: SWAMY, R. N. The alkali-silica reaction in concrete. Glasgow/London: Blackie / New York: Van Nostrand Reinhold, p.1-29.

HASPARYK, N. P. "Investigação dos Mecanismos da Reação Álcali-Agregado - Efeito da Cinza de Casca de Arroz e da Sílica Ativa”. Dissertação de Mestrado, UFG, Escola de Engenharia Civil. Goiânia. 257 p.

HASPARYK, N. P. (2005), "Investigação de Concretos Afetados Pela Reação Álcali-Agregado e Caracterização Avançada do Gel Exsudado”. Tese de Doutorado, Universidade Federal do Rio Grande do Sul. 
HOPPE FILHO, J.; MEDEIROS, M. H. F. de; PEREIRA, E.; HELENE, P. ; ISAIA, G.

C..(2013), "High-volume fly ash concrete with and without hydrated lime: chloride diffusion coefficient from accelerated test". Journal of Materials in Civil Engineering, v. 25, p. 411-418. https://doi.org/10.1061/(ASCE)MT.1943-5533.0000596.

KHAN, Mohammad Iqbal; SIDDIQUE, Rafat. (2011), Utilization of silica fume in concrete: Review of durability properties. Resources, Conservation and Recycling, v. 57, p. 30-35. https://doi.org/10.1016/j.resconrec.2011.09.016

MEHTA, P. K.; MONTEIRO, P. J. M (2008). “Concreto: estrutura, propriedades e materiais”. $3^{\mathrm{a}}$ Edição. São Paulo: IBRACON.

MUNHOZ, Flávio André da Cunha. Efeito de adições ativas na mitigação das reações álcali-sílica e álcali-silicato. 2007. Tese de Doutorado. Universidade de São Paulo.

NEVILLE, A. M (2016). “Propriedades do concreto”. 5a Edição. Porto Alegre: Bookman.

OLLIVER, J. P.; VICHOT, A. (2014), "Durabilidade do concreto: Bases científicas para a formulação de concretos duráveis de acordo com o ambiente”. São Paulo: Ibracon.

SILVA, N. P. (2007), "Reação álcali-agregado nas usinas hidrelétricas do complexo Paulo Afonso / CHESF. Influência da reação nas propriedades do concreto”. Dissertação de Mestrado. Universidade Estadual de São Paulo.

TAYLOR, H. F. W. (1997), “Cement chemistry”. 2 ed. London: Thomas Telford.

TIECHER, F. B. (2006), “Reação álcali-agregado: Avaliação do comportamento de agregados do sul do Brasil quando se altera o cimento utilizado". Dissertação de Mestrado. Universidade Federal do Rio Grande do Sul.

VADUlGA, L. (2002), "Reação Álcali-Agregado: Mapeamento de Agregados Reativos do Estado de São Paulo”. Dissertação de Mestrado. Universidade Estadual de Campinas. 